\title{
One-year mortality, quality of life and predicted life-time cost-utility in critically ill patients with acute respiratory failure
}

\author{
Rita Linko*1, Raili Suojaranta-Ylinen1', Sari Karlsson², Esko Ruokonen³, Tero Varpula1', Ville Pettilä4 and the FINNALI \\ study investigators
}

\begin{abstract}
Introduction: High daily intensive care unit (ICU) costs are associated with the use of mechanical ventilation (MV) to treat acute respiratory failure (ARF), and assessment of quality of life (QOL) after critical illness and cost-effectiveness analyses are warranted.

Methods: Nationwide, prospective multicentre observational study in 25 Finnish ICUs. During an eight-week study period 958 consecutive adult ICU patients were treated with ventilatory support over 6 hours. Of those 958, 619 (64.6\%) survived one year, of whom 288 (46.5\%) answered the quality of life questionnaire (EQ-5D). We calculated EQ-5D index and predicted lifetime quality-adjusted life years (QALYS) gained using the age- and sex-matched life expectancy for survivors after one year. For expired patients the exact lifetime was used. We divided all hospital costs for all ARF patients by the number of hospital survivors, and by all predicted lifetime QALYs. We also adjusted for those who died before one year and for those with missing QOL to be able to estimate the total QALYS.

Results: One-year mortality was 35\% (95\% Cl 32 to 38\%). For the 288 respondents median [IQR] EQ-5D index after one year was lower than that of the age- and sex-matched general population 0.70 [0.45 to 0.89] vs. 0.84 [0.81 to 0.88]. For these 288, the mean (SD) predicted lifetime QALYS was 15.4 (13.3). After adjustment for missing QOL the mean predicted lifetime (SD) QALYs was 11.3 (13.0) for all the 958 ARF patients. The mean estimated costs were $20.739 €$ per hospital survivor, and mean predicted lifetime cost-utility for all ARF patients was $1391 €$ per QALY.

Conclusions: Despite lower health-related QOL compared to reference values, our result suggests that cost per hospital survivor and lifetime cost-utility remain reasonable regardless of age, disease severity, and type or duration of ventilation support in patients with ARF.
\end{abstract}

\section{Introduction}

Mechanical ventilation (MV) to treat acute respiratory failure (ARF) is common and it has been suggested that the use of these methods in ICUs will increase in the future [1]. Higher daily ICU costs are associated with the use of MV [2], so the amount of resources spent on this patient group is an important issue.

Along with a focus shift from short-term to long-term outcomes, the assessment of health-related quality of life (HRQOL) has gained more consideration in patients surviving after critical illness [3,4]. A combination of

* Correspondence: rita.linko@hus.fi

1 Department of Anaesthesia and Intensive Care Medicine, Helsinki University Hospital, Sairaalakatu 1, PL 900, 00029 Helsinki, Finland

Full list of author information is available at the end of the article increased ICU costs and poorer long-term outcomes in patients with acute respiratory distress syndrome (ARDS) $[5,6]$, the most severe form of ARF, and in patients needing prolonged MV [7-9], warrant calculations of costeffectiveness and cost-utility analysis to be made based on HRQOL assessment.

Only two studies focusing on quality-adjusted life years (QALYs) after ARDS are available to date [5,10]. In addition, one cost-effectiveness study of MV [9] and few studies concerning subgroups of mechanically ventilated critical care patients have been published [11-14]. Thus, prospective large observational studies are needed to evaluate the outcomes and costs and predict the lifetime cost-utility of standard critical care in ARF. 
Accordingly, we aimed to analyze one-year mortality and HRQOL of survivors and to predict lifetime QALYs gained and costs per QALY in a large prospective cohort, and relevant subgroups (such as non-invasive ventilation (NIV)), of consecutive ARF patients admitted to Finnish ICUs.

\section{Materials and methods ICUs and study population}

We undertook a prospective multicenter cohort study (FINNALI) in 25 Finnish ICUs. These ICUs cover more than $97 \%$ of the adult population in Finland. During the eight-week period (between 16 April and 10 June, 2007), 2670 admissions in 25 Finnish ICUs were recorded. The cohort comprised all adult ( $\geq 16$ years) patients $(\mathrm{n}=958)$ who received invasive or non-invasive ventilatory support for more than six hours. NIV in this study comprised both continuous positive airway pressure (CPAP) and non-invasive positive pressure ventilation (NPPV). The epidemiology of ARF and the basic demographics of the FINNALI study have been reported previously [15]. This study is a prospective long-term follow up, QOL and cost-utility analysis of the FINNALI study.

\section{Data collection}

Consent from the ethics committee was granted from each hospital. The ethics committees waived the need for informed consent for data registration. For one-year assessment of HRQOL we asked for a written consent. An EQ-5D questionnaire was mailed to patients who had consented. Permission to use the EQ-5D questionnaire was granted by the EuroQOL Group.

Patient characteristics including age, gender, prior functional status, admission reason, severity of acute illness (Simplified Acute Physiology Score (SAPS) II), organ dysfunction score (Sequential Organ Failure Assessment (SOFA)), resource use (Therapeutic Intervention Scoring 76 (TISS)) and length of ICU and hospital stay were obtained from the National ICU quality database (Intensium, Ltd, Kuopio, Finland). Activities of daily life were coded as: 1) able to work, 2) unable to work, but needs no help, 3) needs some help and 4) needs help with activities of daily life. Chronic health state and risk factors 48 hours before ARF were recorded in the clinical report form. The clinical report form data were combined with an internetbased interface to the quality consortium database.

\section{Outcomes}

One-year mortality was obtained from Statistics Finland in 15 May, 2008 [16]. Follow-up time was calculated from the beginning of ARF.

HRQOL was assessed using the EQ-5D questionnaire, a standardized HRQOL instrument developed by the Euro-
Qol Group, which has been found to be suitable and recommended for critically ill patients $[3,10,17]$. In the descriptive part of the EQ-5D, the respondents are asked to describe their health status for five dimensions: mobility, self-care, usual activities, pain/discomfort, and anxiety/depression. Each dimension is rated on a three-level scale: no, some, or severe problems. From the resulting five-digit EQ-5D health profile a weighted EQ index was calculated using the Finnish reference values [18]. Answers to all five domains were required for EQ-5D index calculation. For comparing values of respondents to Finnish population normals [18] the age of the respondent at admission to the ICU was used.

\section{Prediction of lifetime QALYs}

We used the same method as the recently published study of conventional ventilation versus extracorporeal membrane oxygenation (CESAR) [10] for prediction of life time utility. For patients alive at the one-year follow up, the age- and gender-adjusted life expectancies from the year 2007 were obtained from Statistics Finland [16]. First, we predicted lifetime QALYs by multiplying predicted life expectancy after hospital survival by utility values (derived from the EQ-5D) for those survivors with utility values. Second, for patients who died during the one-year follow up, we used exact life-time after hospital discharge.

\section{Calculation of costs}

Based on previous data [2] we reasoned that the mean ICU cost is inadequate for MV patients who consume more resources and individual TISS scores better reflect resource use. We, therefore, used number of individual TISS points for each patient during their ICU stay and the exact number of ward days for cost calculation. The average cost for one TISS-point ( $48 €$ per TISS point) was calculated by dividing the total annual cost of participating ICUs by the sum total of the annual TISS points. Mean ward day price was $416 €$ in Finnish hospitals [19]. Costs after hospital discharge were not available for evaluation. First, all costs (for non-survivors and survivors) were divided by the number of hospital survivors to calculate cost per hospital survivor. Second, the individual costs of all one-year survivors were divided by their predicted total lifetime QALYs to obtain a cost-utility value for only those with complete quality of life (QOL) data.

\section{Adjustment for missing data and sensitivity analysis}

Finally, to confirm the robustness of our estimates we adjusted, first, for the patients who died before one year and, second, for those who did not respond to the QOL questionnaire using the mean QOL of age- and sexmatched respondents for QALY estimates, as previously 
published [19]. We assumed that non-survivors had lower QOL than the whole treated population. Thus, for those who died we used an estimate of $75 \%$ of QOL of the age- and sex-matched QOL of respondents and used the exact lifetime during the first year. For the one-year survivors with missing QOL we used the age- and sexmatched QOL of respondents after comparison to the QOL respondents. Thus, we calculated an estimate of the total predicted lifetime QALYs and cost per QALY for the entire population of 958 ARF patients of the FINNALI study.

\section{Statistical methods}

Data are presented as medians and interquartile ranges (IQR), absolute values and percentages with $95 \%$ confidence intervals $(\mathrm{CI})$ where appropriate, or means (SD). The two-tailed Mann-Whitney U test was used for comparison of continuous variables and the chi-squared test for categorical variables. Multiple groups were compared with Kruskal-Wallis test. EQ-5D index and reference values were analyzed with Wilcoxon's signed matched pair test. $P$ value less than 0.01 was considered significant in all tests. SPSS 15.0 (SPSS inc., Chicago, IL, USA) was used for statistical analyses.

\section{Results}

\section{All 958 ARF patients}

A total of 958 patients were treated for ARF in ICUs during the study period. The flow chart of the study population is shown in Figure 1. Comparison of the characteristics of QOL respondents at one year $(n=288)$ and surviving non-respondents are compared in Table 1. Characteristics of all 958 ARF patients are also included in Table 1 for comparison. Half of the patients (482 of 949; 50.8\%) were able to work before ARF. Only $1.8 \%$ (17 of 949) needed help in their daily activities. Daily activity data were missing for 9 patients.

The one-year mortality rate was $35 \%$ (95\% CI $=32$ to $38 \%)$. Duration of MV was not associated with one-year mortality $(\mathrm{P}=0.211)$. One-year mortality in the group with the shortest ventilatory support (less than 24 hours) was $32 \%$ (95\% CI $=26$ to $37 \%$ ). The mortality $(95 \% \mathrm{CI})$ in groups requiring ventilatory support 24 to 96 hours, 96 hours to 21 days, and over 21 days was 35\% (30 to 40\%), $40 \%$ (34 to $45 \%$ ), and $31 \%$ (14 to $48 \%$ ), respectively. However, a significant difference was found between the different ventilatory support groups. One-year mortality (95\% CI) was lowest, $33 \%(95 \%$ CI $=30$ to $36 \%)$, in patients treated with only invasive ventilation. In patients with NIV only, NIV failure during first six hours and NIV failure after six hours of treatment start were 37\% (28 to $47 \%$ ), $60 \%$ (45 to $76 \%$ ) and $49 \%$ (31 to $66 \%$ ), respectively $(\mathrm{P}=0.001 ; 45 \%$ in all with NIV). One-year mortality in acute lung injury/ARDS patients was 51\% (39 to $64 \%$ ).

\section{The 288 one-year survivors with complete QOL data}

Of the 292 returned EQ-5D questionnaires, 202 (69\%) were given by patients, 42 (14\%) by next of kin, and in 44 (15\%) the respondent was unknown. The EQ-5D index could be calculated for 288 patients after one year $(47 \%$ of 619 one-year survivors, and $67 \%$ of patients with consent). The only differences between the respondents and non-respondents were that the non-respondents were younger and more often patients with emergency admissions (Table 1).

The degree of impairment in each EQ-5D dimension is presented in Table 2. The EQ-5D index at one-year was lower than the age-matched and sex-matched reference value $(0.70(0.45$ to 0.89$)$ vs. 0.84 ( 0.81 to 0.88$), P<0.001)$. The EQ-5D index of the normal population declines with age, so one-year indexes are presented according to different age groups in Figure 2, separately for short postoperative patients (Figure 2a) and all other patients (Figure 2b). No significant difference in EQ-5D indices among one-year survivors was found between the age groups $(P$ $=0.068$ for men, $P=0.265$ for women). However, significant differences were detected in all but the two oldest age groups when compared with the reference population. These 288 patients gained 6,583 life-years and 4,434 predicted lifetime QALYs (2,286 life-years and 1,540 QALYs per 100 one-year survivors). For these 288 oneyear survivors the mean (SD) predicted life-years and lifetime QALYs were 22.9 (14.4) and 15.4 (13.3), respectively. The estimated total costs for these 288 were $4,830,402 €$ and $1,089 €$ per one predicted lifetime QALY.

\section{Adjusted QOL and QALY for whole population}

After adjustment for missing QOL assessments the median (IQR) sum index of EQ-5D for the total population was 0.60 (0.49 to 0.72). Accordingly, our $958 \mathrm{ARF}$ patients were estimated to gain a total of 16,076 life years and 10,857 predicted lifetime QALYs (67 life-years and 44 QALYs in one year per 100 patients).

Overall the calculated costs (of survivors and non-survivors) for ICU and hospital stay were $20,739 €$ per hospital survivor. The proportion of ICU costs with regard to the total hospital cost (ICU and ward costs) were 73\%, $69 \%$ and $87 \%$ for all, survivors and non-survivors, respectively $(P<0.001)$. For all 958 ARF patients (including non-survivors) the mean (SD) predicted life-years was 16.8 (17.2) and lifetime QALYs were 11.3 (13.0), respectively. Our calculation yielded a mean cost per lifetime QALY of $1,391 € / Q A L Y$ with a seven-fold range from $670 €$ to $5,263 €$ according to different age groups, preadmission status, admission type and disease severity (Table 3 ). When patients with short ventilation support (<1day) after surgical procedure were excluded the mean cost per lifetime QALY for the rest of the patients was 1,483€/ QALY. Estimated mean costs, predicted lifetime QALY 
Table 1: Demographic data of study patients. Data are presented as numbers (percentages) or median (interquartile range). Statistical significance was tested between respondents $(n=288)$ and non-respondents of quality of life questionnaire (EQ-5D) at one year

\begin{tabular}{|c|c|c|c|c|}
\hline & \multirow{2}{*}{$\begin{array}{l}\text { ARF patients } \\
\quad(n=958)\end{array}$} & \multicolumn{2}{|c|}{ One-year survivors $(n=619)$} & \multirow[b]{2}{*}{$P$ value } \\
\hline & & $\begin{array}{l}\text { Respondents } \\
\quad(\mathbf{n}=\mathbf{2 8 8})\end{array}$ & $\begin{array}{c}\text { Non-respondents } \\
\quad(\mathbf{n}=\mathbf{3 3 1})\end{array}$ & \\
\hline Age, years & $63(51-74)$ & $64(53-74)$ & $55(41-66)$ & $<0.001$ \\
\hline Gender, male $\mathrm{n}(\%)$ & $637(66.5 \%)$ & $195(67.7 \%)$ & $220(66.5 \%)$ & 0.74 \\
\hline SAPS II, points & $43(31-55)$ & $37(27-49)$ & $37(27-48)$ & 0.99 \\
\hline SOFA, points & $8(6-10)$ & $7(5-9)$ & $7(5-9)$ & 0.81 \\
\hline TISS, points, average & $34(29-41)$ & $34(29-43)$ & $33(28-39)$ & 0.04 \\
\hline TISS, points, total & $151(90-280)$ & $146(95-271)$ & $145(78-264)$ & 0.18 \\
\hline Operative n (\%) & $375(39.1 \%)$ & $143(49.7 \%)$ & $136(41.1 \%)$ & 0.03 \\
\hline Emergency $\mathrm{n}(\%)$ & $821(85.7 \%)$ & $217(75.3 \%)$ & $289(87.3 \%)$ & $<0.001$ \\
\hline $\begin{array}{l}\text { Ventilatory support, } \\
\text { days }\end{array}$ & $2(1-5)$ & $2(1-4)$ & $2(1-5)$ & 0.81 \\
\hline ICU length of stay, days & $3(2-7)$ & $3(2-7)$ & $3(2-7)$ & 0.29 \\
\hline $\begin{array}{l}\text { Hospital length of stay, } \\
\text { days }\end{array}$ & $11(6-21)$ & $13(8-23)$ & $12(7-23)$ & 0.19 \\
\hline ALI/ARDS n (\%) & $68(7.0 \%)$ & $13(4.5 \%)$ & $20(6.0 \%)$ & 0.40 \\
\hline
\end{tabular}

ALI, acute lung injury; ARDS, adult respiratory distress syndrome; ARF, acute respiratory failure; SAPS II, Simplified Acute Physiology Score; SOFA, Sequential Organ Failure Assessment; TISS, Therapeutic Intervention Scoring 76.

and costs per QALY in different age groups of all ARF patients are presented in Figure 3. Both the cost per hospital survivor and the cost per lifetime QALY increased with the number of chronic illnesses and risk factors for ARF. Patients with unsuccessful NIV had the highest costs (42,625 to 44,971€ per hospital survivor). Individual costs and outcomes indicate that for $85 \%$ of our ARF hospital survivors the costs were lower than $20,000 €$ and for $88 \%$ they were lower than $50,000 €$ per predicted lifetime QALY. Among the patients with costs exceeding 20,000€, $27 \%$ (63 of 235) died before hospital discharge.

\section{Discussion}

This prospective multicenter observational study of critically ill patients with ARF in 25 Finnish ICUs found that the 288 one-year survivors with complete QOL data were predicted to gain a mean of 22.9 life-years and 15.4 lifetime QALYs with a cost-utility of $1,089 €$ per lifetime QALY. After adjustment for missing values, the 958 ARF patients were estimated to gain a mean of 16.8 life-years and a mean of 11.3 predicted lifetime QALYs with a costutility of $1,391 €$ per one predicted lifetime QALY.

We used the EQ-5D as a measurement of HRQOL because it has been reported as suitable for critically ill patients [3], it may be answered reliably by the next of kin $[20,21]$, and it has been previously used for cost-utility analysis in the critically ill [19,22,23]. More recently, a cost-utility evaluation alongside a large randomized trial comprising ARF and treatment with extracorporeal membrane oxygenation also used EQ-5D questionnaires (six months after critical illness) with UK tariff values for utility [10]. In concordance with our study, that study assumed a utility of 0 at the time of onset of treatment. This approach differs from cost-utility calculations for other medical treatment where a control group with no treatment is included. This kind of study design in ARF patients without MV would be unfeasible and unethical. Thus, an ordinary cost-utility analysis based on QOL comparison before and after treatment is not suitable in this specific setting of life-threatening illness where withdrawing MV means death. In the critical care setting, the ordinary concept of a control group seems to be only valid with regard to treatments, which are added on top of the vital life support such as MV, as in the CESAR study [10]. Accordingly, we did not include any comparisons to pre-ICU QOL but evaluated only QOL after critical illness for utility. 


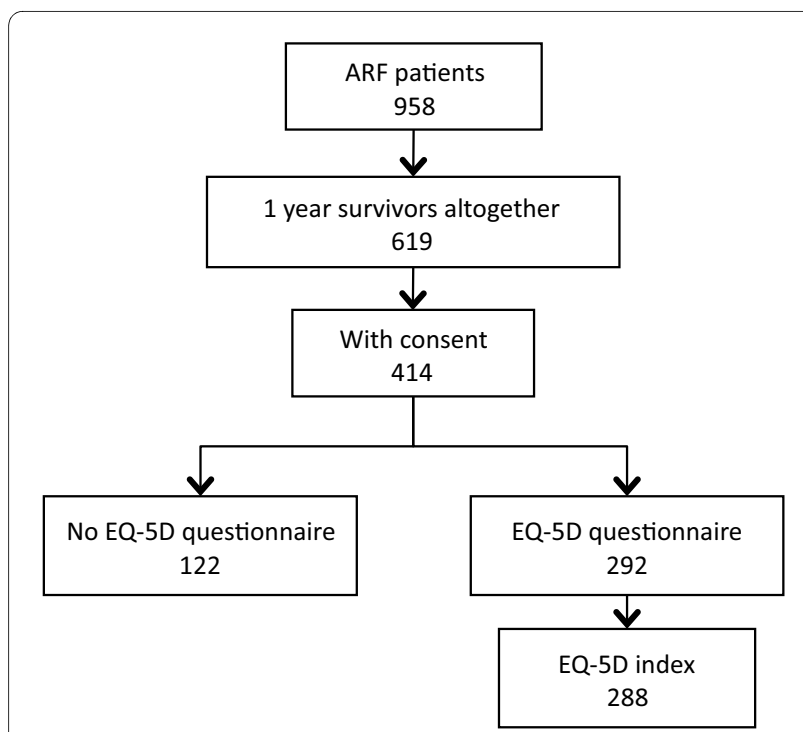

Figure 1 Flow-chart of study population for quality of life and cost-utility evaluation. ARF, acute respiratory failure; QALY, qualityadjusted life years.

In agreement with previous studies [24-28] we detected lower QOL after ARF compared with the age-matched and sex-matched reference values. HRQOL decreases after ARF [29] and ARDS [5], and it may even be lower after ARDS compared with other critically ill patients

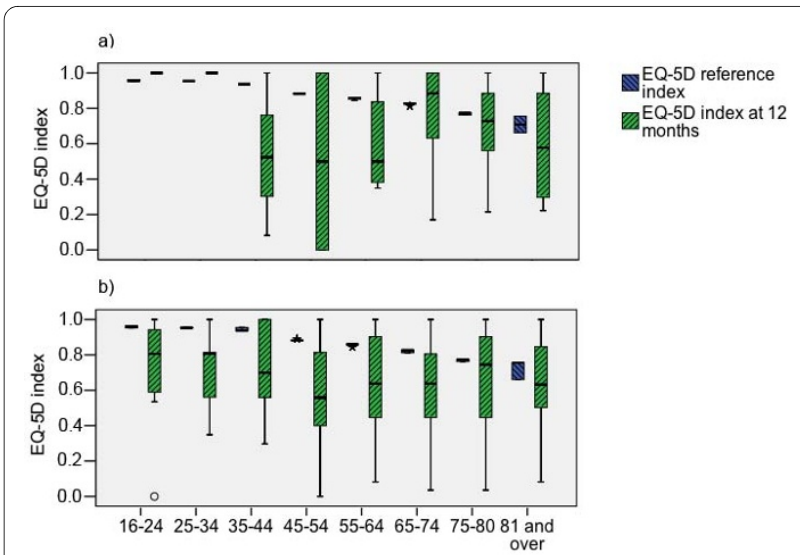

Figure $2 \mathrm{EQ}-5 \mathrm{D}$ index of respondents of acute respiratory failure at one year compared with reference values. Patients are divided to (a) post-operative patients with short ( $<1$ day) ventilatory support and (b) other patients. $P=0.005$ in age group 65 to 74 years.

[30]. Of note, the QOL after ARF may be largely influenced by severity of dysfunction and mortality rate.

The one-year mortality in this national cohort of ARF patients was $35 \%$, which is below the previously reported range (range for one-year survival 44 to $65 \%$ ) $[5,7,29,31]$. However, different definitions limit definite conclusions. The inclusion criteria for this study were a need for ventilatory support exceeding six hours using either invasive

Table 2: Distribution of responses to EQ-5D modalities at one year. Data are presented as number (percentage)

Mobility

Self-care

Usual activities

Pain/discomfort 
Table 3: Predicted cost-utilities in subgroups of patients with acute respiratory failure

\begin{tabular}{|c|c|c|c|c|c|}
\hline & n & $\begin{array}{c}\text { Gained survival } \\
\text { (years) } \\
\text { mean (SD) }\end{array}$ & $\begin{array}{c}\text { QALYs (years) } \\
\text { mean (SD) }\end{array}$ & $\begin{array}{c}\text { Cost/hospital } \\
\text { survivor } \\
€\end{array}$ & $\begin{array}{c}\text { Cost/QALY } \\
€\end{array}$ \\
\hline \multicolumn{6}{|l|}{ Age (years) } \\
\hline$\leq 51$ & 252 & $36(19)$ & $25(16)$ & 19,195 & 670 \\
\hline $52-63$ & 236 & $17(11)$ & $11(8)$ & 21,069 & 1,582 \\
\hline $64-74$ & 251 & $9(8)$ & $6(6)$ & 21,499 & 2,620 \\
\hline$\geq 75$ & 219 & $4(5)$ & $3(3)$ & 21,737 & 5,263 \\
\hline \multicolumn{6}{|l|}{ SAPS II (points) } \\
\hline$\leq 31$ & 253 & $28(18)$ & $20(15)$ & 15,187 & 726 \\
\hline $32-43$ & 246 & $18(16)$ & $11(12)$ & 22,545 & 1,656 \\
\hline $44-55$ & 222 & $13(15)$ & $8(11)$ & 23,565 & 2,026 \\
\hline$\geq 56$ & 237 & $8(13)$ & $5(9)$ & 24,760 & 2,560 \\
\hline \multicolumn{6}{|l|}{ Activities of daily life } \\
\hline Able to work & 482 & $23(19)$ & $16(14)$ & 19,718 & 1,028 \\
\hline $\begin{array}{l}\text { Unable to work but needs no } \\
\text { help }\end{array}$ & 337 & $12(13)$ & $8(9)$ & 21,665 & 2,075 \\
\hline Needs some help & 113 & $8(12)$ & $5(9)$ & 21,512 & 2,722 \\
\hline $\begin{array}{l}\text { Needs help to activities of daily } \\
\text { life }\end{array}$ & 17 & $8(15)$ & $5(12)$ & 30,653 & 3,450 \\
\hline \multicolumn{6}{|l|}{ Admission type } \\
\hline Elective & 133 & $16(14)$ & $12(12)$ & 17,273 & 1,283 \\
\hline Emergency & 821 & $17(18)$ & $11(13)$ & 21,462 & 1,410 \\
\hline \multicolumn{6}{|l|}{ Ventilatory support } \\
\hline NIV only & 105 & $15(17)$ & $11(14)$ & 13,154 & 956 \\
\hline Invasive ventilation only & 775 & $17(17)$ & $12(13)$ & 20,065 & 1,313 \\
\hline $\begin{array}{l}\text { NIV and invasive ventilation } \\
\text { before } 6 \text { hours }\end{array}$ & 43 & $11(16)$ & $6(9)$ & 42,625 & 3,733 \\
\hline $\begin{array}{l}\text { NIV and invasive ventilation } \\
\text { after } 6 \text { hours }\end{array}$ & 35 & $13(17)$ & $8(11)$ & 44,971 & 3,499 \\
\hline \multicolumn{6}{|l|}{ Chronic diseases, count } \\
\hline 0 & 425 & $23(19)$ & $16(15)$ & 19,065 & 966 \\
\hline 1 & 320 & $13(15)$ & $8(11)$ & 22,583 & 1,936 \\
\hline 2 & 158 & $10(11)$ & $7(9)$ & 21,699 & 2,337 \\
\hline 3 & 47 & $9(9)$ & $6(6)$ & 24,400 & 3,102 \\
\hline 4 & 8 & $8(9)$ & $4(5)$ & 34,108 & 3,910 \\
\hline \multicolumn{6}{|l|}{ ARF risk factors $\mathbf{4 8}$ hours before } \\
\hline Sepsis & 136 & $14(15)$ & $9(12)$ & 37,219 & 2,599 \\
\hline Cardiac insufficiency & 192 & $9(12)$ & $6(8)$ & 27,322 & 2,779 \\
\hline Pneumonia & 114 & $14(16)$ & $9(12)$ & 26,368 & 2,106 \\
\hline $\begin{array}{l}\text { Post-operative with ventilatory } \\
\text { support }<1 \text { day }\end{array}$ & 132 & $17(15)$ & $12(12)$ & 11,025 & 836 \\
\hline
\end{tabular}

Chronic diseases include chronic obstructive pulmonary disease, chronic restrictive pulmonary disease, chronic heart disease, diabetes mellitus, immunodeficiency, neuromuscular disease.

ARF, acute respiratory failure; NIV, non-invasive ventilation; SAPS II, Simplified Acute Physiology Score; SD, standard deviation; QALY, qualityadjusted life year. 


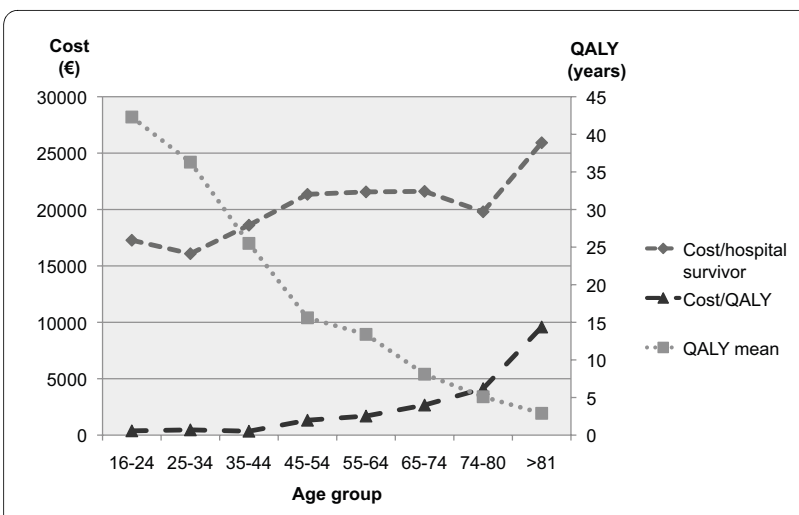

Figure 3 Estimated mean costs and predicted lifetime quality-adjusted life years (QALY) and costs per QALY in different age groups.

or non-invasive methods. Surprisingly, survival in the group that received the longest ventilatory support, over 21 days was as low as $31 \%$, lower than the $51 \%$ and $58 \%$ in previous reports of prolonged MV [9,32]. Differences in decisions to withhold or withdraw treatments after a period of treatment effort may be one plausible explanation for this. In addition, the one-year mortality rate for those with NIV was $45 \%$ compared with $33 \%$ for those with invasive ventilation. Thus, studies in ARF patients including only patients with a special type or specified duration of MV may report varying survival rates. Thus, the varying inclusion criteria of different studies affect the predicted lifetime cost-utility.

Health care technologies that cost less than $\$ 20,000$ per QALY are widely accepted, but even cut-off values as high as $\$ 100,000$ per QALY have been considered [33]. The National Institute of Clinical Excellence (NICE) would be unlikely to reject any technology with a ratio in the range of $£ 5,000$ to $£ 15,000$ per QALY solely on the ground of cost-ineffectiveness [34]. Our sensitivity analysis (Table 3) showed that the cost remained below the lower cut-off value of NICE in all subsets. Thus, we consider our treatment cost-effective. Furthermore, compared with the Gross Domestic Product per capita (in Finland \$37,200 2007 [35]) the cost-utility (as €/QALY) was lower in all subgroups of ARF patients. We detected remarkable differences in cost per QALY with increasing age and disease severity. Our finding is in parallel with the study by Hamel and colleagues in patients with pneumonia and ARDS [14]. However, in their study the cost range was considerably higher, from $\$ 19,000$ to $\$ 200,000$ per QALY according to different risk estimates and sensitivity analysis. Even without costs after discharge from hospital, hospital cost was higher than in our study. Even higher hospital costs $(\$ 165,075$ to $\$ 423,596)$ have been reported for prolonged MV [9]. In addition, diagnostic category also influences cost among the critically ill $[20,36,37]$.
Pneumonia and ARDS have been among the most expensive diagnosis groups in previous studies $[14,35,38]$ and in a recent review [39]. In the absence of a gold standard for cost-effectiveness analysis, different ways to calculate costs and report the analysis make direct cost comparisons challenging [40].

To the best of our knowledge, this is the largest costutility analysis based on a nationwide prospective multicenter cohort of consecutive ARF patients. For QOL assessment we used EQ-5D, which is frequently used for QALY assessment in health care [41] and, despite its limitations, recommended for evaluations in the critical care setting [3], and reported recently in this setting with similar approach [10].

Our study has some limitations. First, we used an estimation of life expectancy for survivors to enable cost-utility over a lifetime horizon to be calculated, as previously published $[10,19]$. This approach includes an assumption that the life-time for survivors of ARF will be comparable with that of an age-matched and sex-matched population. We used one-year follow up instead of six months, as in the CESAR trial [10]. The survival after critical illness has been shown to be comparable with the Finnish population based reference values after two years [42]. However, we consider our follow up to be sufficiently long because mortality in our ARF patients was stable after six months, in keeping with previous reports $[5,6,43]$. Second, QOL was evaluated after one year and may not, even then, reliably reflect the QOL for the remainder of life. On the other hand, one-year follow up is generally accepted to be adequate $[4,44]$. Third, multiplying the life-time estimate by QOL at one-year follow up without adjusting for time differences does not take into account the gradual decline of QOL with age. However, we did not find any significant differences between the respondents of different age groups. In reference EQ-5D sum index values, the decline from the youngest to the oldest is 15 to $20 \%$ in the Finnish reference population. This decline would, therefore, correspond to a less than $10 \%$ increase in the estimated cost per QALY.

Fourth, all costs per QALY estimates are sensitive to differences in patient demographics and outcome. We, therefore, calculated costs separately for those with QOL assessment and also adjusted for patients with missing data. If we had only included one-year survivors, as some other studies with different critically ill patients [45], with QOL data available, that would have caused a significant bias because the surviving patients are not representative for the whole ICU population. We, therefore, also adjusted for missing patients with an approach similar to other studies $[10,19,46]$ and performed a sensitivity analysis for different subgroups of patients ending up with acceptable estimates of up to 5,263€ per QALY for all these subgroups. Fifth, of note, these estimates do not 
include post-discharge costs or annual health service use as in some other studies $[7,14]$. Thus, our estimates only include hospital costs for the ARF treatment and underestimate the total costs of care during the first year.

Finally, precise costs of the care are difficult to gather and to compare with other studies because different calculations are used for ICU and hospital charges. We did not register the costs for each patient using a bottom-up method $[40,47]$. In order to be comparable with the latest Finnish study in severe sepsis [19] we used the same methodology for ICU and hospital costs adjusting for the use of ICU resources using individual TISS points for each patient in our calculations as previously published [48].

\section{Conclusions}

We conclude that two-thirds of our ARF patients were alive at one-year follow up. Despite lower HRQOL compared with population reference value, our results suggest that the cost per one predicted lifetime QALY remains reasonable in these patients with ARF regardless of age, disease severity, or type and duration of MV.

\section{Key messages}

- One-year mortality in ARF patients was 35\% (95\% $\mathrm{CI}=32$ to $38 \%$ ).

- EQ-5D index after one year was lower than that of an age-matched and sex-matched general population. - Cost per hospital survivor and life-time cost-utility remain reasonable regardless of age, disease severity, and type or duration of ventilatory support in patients with ARF.

\begin{abstract}
Abbreviations
ARDS: adult respiratory distress syndrome; ARF: acute respiratory failure; $\mathrm{Cl}$ : confidence interval; CPAP: continuous positive airway pressure; HRQOL: healthrelated quality of life; IQR: interquartile range; MV: mechanical ventilation; NIV: non-invasive ventilation; NPPV: noninvasive positive-pressure ventilation; QALY: quality-adjusted life year; QOL: quality of life; SAPS: Simplified Acute Physiology Score; SD: standard deviation; SOFA: Sequential Organ Failure Assessment; TISS: Therapeutic Intervention Scoring 76.
\end{abstract}

\section{Competing interests}

The authors declare that they have no competing interests.

\section{Authors' contributions}

$R L, T V, E R$ and $V P$ were involved in the study design. $R L$ and $V P$ analyzed the data, made the statistical analysis and drafted the manuscript. SK, RSY, TV and ER participated in drafting and revision of the manuscript. All authors were involved in data acquisition and read and approved the final manuscript.

\section{Acknowledgements}

We thank Ms Alisa Higgins (MPH) for her valuable review of the manuscript and editing of the language. We also owe our gratitude to all nurses and doctors in the participating ICUs for the support to this study. We appreciate the help of study nurses Sari Sutinen and Leena Pettilä in acquiring the QOL assessments. The FINNALI Study group: Participating hospitals and investigators: Satakunta Central Hospital - Dr. Vesa Lund, Päivi Tuominen, Pauliina Perkola; East Savo Central Hospital- Dr. Markku Suvela, Sirpa Kauppinen, Anne-Marja Turkulainen; Central Finland Central Hospital- Dr. Raili Laru-Sompa, Tiina Kirkhope, Sirpa Nykänen; South Savo Central Hospital- Dr. Heikki Laine, Kirsi Reponen, Pekka
Kettunen; North Karelia Central Hospital - Dr. Matti Reinikainen, Tanja Eiserbeck, Helena Jyrkönen; Seinäjoki Central Hospital - Dr. Kari Saarinen, Dr. Matti Viitanen, Niina Siirilä, Johanna Soini; South Karelia Central Hospital - Dr. Seppo Hovilehto, Dr. Anne Kirsi, Dr. Pekka Tiainen, Sanna Asikainen; Päijät-Häme Central Hospital - Dr. Pekka Loisa; Vaasa Central Hospital, Dr. Pentti Kairi; KantaHäme Central Hospital - Dr. Risto Puolakka, Piia Laitinen, Tarja Heikkilä; Lapp Central Hospital - Dr. Outi Kiviniemi, Tarja Laurila, Tiina Pikkuhookana; KeskiPohjanmaa Central Hospital - Dr. Samuli Forsström, Dr. Tadeusz Kaminski, Tuija Kuusela; Kymenlaakso Central Hospital - Dr. Jussi Pentti, Dr. Seija Alila, Reija Koskinen; Helsinki University Hospital - Jorvi Hospital- Dr. Tero Varpula, Mira Rahkonen; - Meilahti Hospital ICU, Dr. Anne Kuitunen, Dr. Anna-Maija Korhonen, Dr. Rita Linko, Dr. Marjatta Okkonen, Janne Myller, Jarmo Pekkola, Leena Pettilä, Sari Sutinen; - Meilahti Hospital, Cardiac Surgical ICU - Dr. Raili Suojaranta-Ylinen, Dr. Sinikka Kukkonen, Elina Nurmi-Toivonen; - Meilahti Hospital, Department of Medicine - Dr. Tom Bäcklund, Dr. Juhani Rossinen, Riina Mäkelä; - Töölö Hospital - Dr. Janne Reitala, Dr. Jyrki Vuola, Raija Niemi, Marja-Leena Pihlajamaa, Aira Uusipaavalniemi; - Surgical Hospital - Dr. Anna-Maria Koivusalo, Pasi Kyllönen; Turku University Hospital - Dr. Juha Perttilä, Dr. Erkki Kentala, Dr. Olli Arola, Dr. Outi Inkinen, Jutta Kotamäki; Tampere University Hospital - Dr. Sari Karlsson, Dr. Jyrki Tenhunen, Minna-Liisa Peltola, Sanna Mäkinen, Anna-Liina Korkala, Samuli Kortelainen; Kuopio University Hospital - Dr. Esko Ruokonen, Dr. Ilkka Parviainen, Sari Rahikainen, Elina Halonen; Oulu University Hospital - Dr. Tero Ala-Kokko, Dr. Jouko Laurila, Sinikka Sälkiö, Tarja Lamberg.

We acknowledge EVO-grants TYH 7250 and TYH 8240 from Helsinki University Hospital, and a grant from Instrumentarium Scientific Foundation.

\section{Author Details}

'Department of Anaesthesia and Intensive Care Medicine, Helsinki University Hospital, Sairaalakatu 1, PL 900, 00029 Helsinki, Finland, 2Department of Intensive Care Medicine, Tampere University Hospital, Teiskontie 35, Fl-33520 Tampere, Finland, ${ }^{3}$ Division of Intensive Care, Kuopio University Hospital, Yliopistonranta 1E, Fl-70211 Kuopio, Finland and ${ }^{4}$ Australian and New Zealand Intensive Care Research Centre, School of Public Health, Monash University, The Alfred Hospital, Commercial Rd, Melbourne VIC 3004 Melbourne, Australia

Received: 4 November 2009 Revised: 15 February 2010

Accepted: 12 April 2010 Published: 12 April 2010

\section{References}

1. Needham DM, Bronskill SE, Calinawan JR, Sibbald WJ, Pronovost PJ, Laupacis A: Projected incidence of mechanical ventilation in Ontario to 2026: Preparing for the aging baby boomers. Crit Care Med 2005, 33:574-579.

2. Dasta JF, McLaughlin TP, Mody SH, Piech CT: Daily cost of an intensive care unit day: the contribution of mechanical ventilation. Crit Care Med 2005, 33:1266-1271

3. Angus DC, Carlet J, 2002 Brussels Roundtable Participants: Surviving intensive care: a report from the 2002 Brussels Roundtable. Intensive Care Med 2003, 29:368-377.

4. Dowdy DW, Eid MP, Dennison CR, Mendez-Tellez PA, Herridge MS, Guallar E, Pronovost PJ, Needham DM: Quality of life after acute respiratory distress syndrome: a meta-analysis. Intensive Care Med 2006, 32:1115-1124.

5. Angus DC, Musthafa AA, Clermont G, Griffin MF, Linde-Zwirble WT, Dremsizov TT, Pinsky MR: Quality-adjusted survival in the first year after the acute respiratory distress syndrome. Am J Respir Crit Care Med 2001, 163:1389-1394.

6. Cheung AM, Tansey CM, Tomlinson G, Diaz-Granados N, Matte A, Barr A, Mehta S, Mazer CD, Guest CB, Stewart TE, Al-Saidi F, Cooper AB, Cook D, Slutsky AS, Herridge MS: Two-year outcomes, health care use, and costs of survivors of acute respiratory distress syndrome. Am J Respir Crit Care Med 2006, 174:538-544.

7. Douglas SL, Daly BJ, Gordon N, Brennan PF: Survival and quality of life: short-term versus long-term ventilator patients. Crit Care Med 2002, 30:2655-2662.

8. Combes A, Costa MA, Trouillet JL, Baudot J, Mokhtari M, Gibert C, Chastre $\mathrm{J}$ : Morbidity, mortality, and quality-of-life outcomes of patients requiring $>$ or $=14$ days of mechanical ventilation. Crit Care Med 2003, 31:1373-1381. 
9. Cox CE, Carson SS, Lindquist JH, Olsen MK, Govert JA, Chelluri L, Quality of Life After Mechanical Ventilation in the Aged (QOL-MV) Investigators: Differences in one-year health outcomes and resource utilization by definition of prolonged mechanical ventilation: a prospective cohort study. Crit Care 2007, 11:R9.

10. Peek GJ, Mugford M, Tiruvoipati R, Wilson A, Allen E, Thalanany MM, Hibbert CL, Truesdale A, Clemens F, Cooper N, Firmin RK, Elbourne D, for the CESAR trial collaboration: Efficacy and economic assessment of conventional ventilatory support versus extracorporeal membrane oxygenation for severe adult respiratory failure (CESAR): a multicentre randomised controlled trial. Lancet 2009, 374:1351-1363.

11. Anon JM, Garcia de Lorenzo A, Zarazaga A, Gomez-Tello V, Garrido G: Mechanical ventilation of patients on long-term oxygen therapy with acute exacerbations of chronic obstructive pulmonary disease: prognosis and cost-utility analysis. Intensive Care Med 1999, 25:452-457.

12. Wachter RM, Luce JM, Safrin S, Berrios DC, Charlebois E, Scitovsky AA: Cost and outcome of intensive care for patients with AIDS, Pneumocystis carinii pneumonia, and severe respiratory failure. JAMA 1995 273:230-235.

13. Mayer SA, Copeland D, Bernardini GL, Boden-Albala B, Lennihan L, Kossoff $\mathrm{S}$, Sacco RL: Cost and outcome of mechanical ventilation for lifethreatening stroke. Stroke 2000, 31:2346-2353.

14. Hamel MB, Phillips RS, Davis RB, Teno J, Connors AF, Desbiens N, Lynn J, Dawson NV, Fulkerson W, Tsevat J: Outcomes and cost-effectiveness of ventilator support and aggressive care for patients with acute respiratory failure due to pneumonia or acute respiratory distress syndrome. Am J Med 2000, 109:614-620.

15. Linko R, Okkonen M, Pettilä V, Perttilä J, Parviainen I, Ruokonen E, Tenhunen J, Ala-Kokko T, Varpula T, The FINNALI-study group: Acute respiratory failure in intensive care units. FINNALI: a prospective cohort study. Intensive Care Med 2009, 35:1352-1361.

16. Statistics Finland [http://www.stat.fi]

17. EuroQol--a new facility for the measurement of health-related quality of life. The EuroQol Group. Health Policy 1990, 16:199-208.

18. Ohinmaa A, Sintonen $\mathrm{H}$ : Quality of life of Finnish population measures by EuroQol. EuroQol, Plenary Meeting, Barcelona 1995, 3-5 October. Discussion papers, Catalan Institute of Public Health, Barcelona 1996:161-172

19. Karlsson S, Ruokonen E, Varpula T, Ala-Kokko TI, Pettilä V, Finnsepsis Study Group: Long-term outcome and quality-adjusted life years after severe sepsis. Crit Care Med 2009, 37:1268-1274.

20. Badia X, Diaz-Prieto A, Rue M, Patrick DL: Measuring health and health state preferences among critically ill patients. Intensive Care Med 1996, 22:1379-1384.

21. Badia X, Diaz-Prieto A, Gorriz MT, Herdman M, Torrado H, Farrero E, Cavanilles JM: Using the EuroQol-5D to measure changes in quality of life 12 months after discharge from an intensive care unit. Intensive Care Med 2001, 27:1901-1907.

22. Sznajder M, Aegerter P, Launois R, Merliere Y, Guidet B, CubRea : A costeffectiveness analysis of stays in intensive care units. Intensive Care Med 2001, 27:146-153.

23. Ridley S, Morris S: Cost effectiveness of adult intensive care in the UK. Anaesthesia 2007, 62:547-554.

24. Ridley SA, Chrispin PS, Scotton H, Rogers J, Lloyd D: Changes in quality of life after intensive care: comparison with normal data. Anaesthesia 1997, 52:195-202

25. Wehler M, Geise A, Hadzionerovic D, Aljukic E, Reulbach U, Hahn EG, Strauss R: Health-related quality of life of patients with multiple organ dysfunction: individual changes and comparison with normative population. Crit Care Med 2003, 31:1094-1101.

26. Graf J, Koch M, Dujardin R, Kersten A, Janssens U: Health-related quality of life before, 1 month after, and 9 months after intensive care in medical cardiovascular and pulmonary patients. Crit Care Med 2003, 31:2163-2169.

27. Cuthbertson BH, Scott J, Strachan M, Kilonzo M, Vale L: Quality of life before and after intensive care. Anaesthesia 2005, 60:332-339.

28. Hofhuis JG, Spronk PE, van Stel HF, Schrijvers GJ, Rommes JH, Bakker J: The impact of critical illness on perceived health-related quality of life during ICU treatment, hospital stay, and after hospital discharge: a long-term follow-up study. Chest 2008, 133:377-385.

29. Garland A, Dawson NV, Altmann I, Thomas CL, Phillips RS, Tsevat J, Desbiens NA, Bellamy PE, Knaus WA, Connors AF Jr, SUPPORT
Investigators: Outcomes up to 5 years after severe, acute respiratory failure. Chest 2004, 126:1897-1904.

30. Davidson TA, Caldwell ES, Curtis JR, Hudson LD, Steinberg KP: Reduced quality of life in survivors of acute respiratory distress syndrome compared with critically ill control patients. JAMA 1999, 281:354-360.

31. Chelluri L, Im KA, Belle SH, Schulz R, Rotondi AJ, Donahoe MP, Sirio CA, Mendelsohn AB, Pinsky MR: Long-term mortality and quality of life after prolonged mechanical ventilation. Crit Care Med 2004, 32:61-69.

32. Carson SS, Garrett J, Hanson LC, Lanier J, Govert J, Brake MC, Landucci DL, Cox CE, Carey TS: A prognostic model for one-year mortality in patients requiring prolonged mechanical ventilation. Crit Care Med 2008 , 36:2061-2069.

33. Laupacis A, Feeny D, Detsky AS, Tugwell PX: How attractive does a new technology have to be to warrant adoption and utilization? Tentative guidelines for using clinical and economic evaluations. CMAJ 1992, 146:473-481.

34. Rawlins MD, Culyer AJ: National Institute for Clinical Excellence and its value judgements. BMJ 2004, 329:224-227.

35. Country Comparison of the World [https://www.cia.gov/library/ publications/the-world-factbook/fields/2004.html]

36. Ridley S, Biggam M, Stone P: A cost-benefit analysis of intensive therapy. Anaesthesia 1993, 48:14-19.

37. lapichino G, Radrizzani D, Simini B, Rossi C, Albicini M, Ferla L, Colombo A, Pezzi A, Brazzi L, Melotti R, Rossi G, Italian Group for the Evaluation of Interventions in Intensive Care Medicine: Effectiveness and efficiency of intensive care medicine: variable costs in different diagnosis groups. Acta Anaesthesiol Scand 2004, 48:820-826.

38. Rossi C, Simini B, Brazzi L, Rossi G, Radrizzani D, lapichino G, Bertolini G, Gruppo Italiano per la Valutazione degli Interventi in Terapia Intensiva: Variable costs of ICU patients: a multicenter prospective study. Intensive Care Med 2006, 32:545-552.

39. Talmor D, Shapiro N, Greenberg D, Stone PW, Neumann PJ: When is critical care medicine cost-effective? A systematic review of the costeffectiveness literature. Crit Care Med 2006, 34:2738-2747.

40. Gyldmark M: A review of cost studies of intensive care units: problems with the cost concept. Crit Care Med 1995, 23:964-972.

41. Rasanen $P$, Roine $E$, Sintonen $H$, Semberg-Konttinen $V$, Ryynanen OP, Roine R: Use of quality-adjusted life years for the estimation of effectiveness of health care: A systematic literature review. Int J Technol Assess Health Care 2006, 22:235-241.

42. Niskanen M, Kari A, Halonen P: Five-year survival after intensive care-comparison of 12,180 patients with the general population. Finnish ICU Study Group. Crit Care Med 1996, 24:1962-1967.

43. Herridge MS, Cheung AM, Tansey CM, Matte-Martyn A, Diaz-Granados N, Al-Saidi F, Cooper AB, Guest CB, Mazer CD, Mehta S, Stewart TE, Barr A Cook D, Slutsky AS, Canadian Critical Care Trials Group: One-year outcomes in survivors of the acute respiratory distress syndrome. $\mathrm{N}$ Engl J Med 2003, 348:683-693.

44. Understanding costs and cost-effectiveness in critical care: report from the second American Thoracic Society workshop on outcomes research. Am J Respir Crit Care Med 2002, 165:540-550.

45. Graf J, Muhlhoff C, Doig GS, Reinartz S, Bode K, Dujardin R, Koch KC, Roeb $\mathrm{E}$, Janssens $\mathrm{U}$ : Health care costs, long-term survival, and quality of life following intensive care unit admission after cardiac arrest. Crit Care 2008, 12:R92

46. Kaarlola A, Tallgren M, Pettilä V: Long-term survival, quality of life, and quality-adjusted life-years among critically ill elderly patients. Crit Care Med 2006, 34:2120-2126.

47. Jegers M, Edbrooke DL, Hibbert CL, Chalfin DB, Burchardi H: Definitions and methods of cost assessment: an intensivist's guide. ESICM section on health research and outcome working group on cost effectiveness. Intensive Care Med 2002, 28:680-685.

48. Dickie H, Vedio A, Dundas R, Treacher DF, Leach RM: Relationship between TISS and ICU cost. Intensive Care Med 1998, 24:1009-1017.

\section{doi: $10.1186 /$ cc8957}

Cite this article as: Linko et al., One-year mortality, quality of life and predicted life-time cost-utility in critically ill patients with acute respiratory failure Critical Care 2010, 14:R60 